San Jose State University

From the SelectedWorks of Lili Luo

2015

\title{
Consumer Health Reference Interview: Ideas for Public Librarians
}

Lili Luo, San Jose State University 
RUNNING HEAD: CONSUMER HEALTH REFERENCE FOR PUBLIC LIBRARIANS

\title{
Consumer Health Reference Interview:
}

\section{Ideas for Public Librarians}

\author{
Lili Luo \\ School of Information \\ San Jose State University \\ One Washington Square \\ San Jose, CA 95192-0029 \\ Lili.luo@sjsu.edu
}

Acknowledgement: The author would like to thank San Jose State University RSCA Grant for supporting this study.

[This is the preprint. Please cite it as "Luo, L. (2015). Consumer health reference interview: Ideas for public librarians. Public Library Quarterly, 34(4), 328-353."] 
2|Pag e 


\section{Consumer Health Reference Interview: Ideas for Public Librarians}

\section{Abstract}

This two-stage study seeks to help public librarians become better prepared, and more confident and competent when answering medical/health questions. At the first stage, eleven barriers public librarians often encounter in the consumer health reference interview were identified through a comprehensive literature review, and at the second stage, input from professional consumer health librarians on how to overcome the barriers was gathered via a qualitative survey. Findings of the study provide concrete and practical strategies that will help public librarians more successfully conduct the reference interview to assist library users in their health information seeking journey.

\section{Introduction}

There has been a growing demand for consumer health information as patients become more active in managing their health and health care (Kaiser 2005). Merely $36 \%$ of adults considered their physicians to be a primary source of medical information (Sprang and Baker 2000). Nowadays, patients are no longer passive recipients of medical care. To better meet their health care needs, it is important to have efficient and effective access to high-quality and comprehensible health information, and public libraries are uniquely positioned to play a supporting role in this regard (Lyon 2001; Baker and Manbeck 2002). They provide a no-cost, convenient way to assist the public in navigating health information resources, fulfilling their health information needs, and ultimately improving their health literacy (Zionts, Apter, Kuchta, and Greenhouse 2010). The public library is often the first place many people consult when 
seeking information on important health topics, such as health care coverage eligibility, disease prevention and treatment (Zionts et al. 2010; Westermann-Cicio 2003). Health information is generally considered one of the top-five or top-ten topics of interest to public library users, and health-related questions account for as many as $60 \%$ of the total reference questions (Wood, Lyon, Schelle, Kitendaugh, Cid and Siegel 2000).

The number of health-related questions received by public libraries has steadily increased in the past three decades and escalated exponentially since the late 1990s (Parker and Kreps 2005). With the Affordable Care Act taking effect, it is expected that questions related to health insurance coverage will increase significantly. Yet many public librarians are not comfortable, confident or competent in providing reference service to health information seekers due to concerns such as an inadequate understanding of health literacy, fear of providing misinformation and possible intrusion on user privacy (Wood et al. 2000; Parker and Kreps 2005; Borman and McKenzie 2005). As a result, the level of service delivered by public librarians has shown substantial variability (Wood et al., 2000). Since users may rely on the health information obtained from libraries to make important decisions regarding their personal wellbeing, it is suggested that librarians be mindful of the far-reaching implications of their service and be adequately prepared (Orban, 2005).

In a nation-wide study to identify public librarians' need for professional development in the provision of consumer health information, Luo and Ta Park (2013) identified health reference interview to be one of the most desired training topics. The National Network of Libraries of Medicine believes that consumer health questions present special challenges to the reference interview process (NNLM 2014) - consumers may have incomplete information about their 
health condition and may be unfamiliar with medical terminology; the information needed may be about a sensitive issue, such as a mental health condition; the consumer may be nervous, embarrassed, upset, and emotional; often the individual has been newly diagnosed, or a loved one has been newly diagnosed; consumers may have unreasonable expectations, for instance, they may want a straightforward answer to a complex medical question, when in reality, this kind of information may be difficult or impossible to find; consumers may be concerned about confidentiality, anonymity, and security, especially about personal health information transmitted electronically to a librarian; consumers may be confused about the role of the librarian, and they might assume that the librarian can advise them on making health care decisions; librarians may be concerned about providing incorrect information or negative information (e.g., the expected life span for someone with a specific medical condition).

To help public librarians, who tend to be generalists and usually receive no training in consumer health information services, become better prepared in answering consumer health questions, this study seeks to identify the best practices for consumer health reference interview through an in-depth literature analysis and a qualitative survey. Results of the study will yield insights regarding how to address the challenges inherent in consumer health reference transactions and how to successfully conduct the reference interview. Educators can also draw on this knowledge as they develop programs that prepare public librarians for consumer health information services.

\section{Study Procedures}

The study was a two-stage study. The first stage consisted of a comprehensive review of the literature about consumer health information services in public libraries. The literature review 
identified an array of barriers public librarians encounter when answering consumer health questions, such as barriers related to interpreting library users' information needs, barriers related to locating/searching/evaluating consumer health information resources, and barriers related to handling health questions of sensitive nature. At the second stage, an online qualitative survey study was conducted among professional consumer health librarians at medical or health libraries, seeking their input regarding how to help public librarians successfully conduct the consumer health reference interview.

The survey questionnaire was developed on the basis of the literature review. It contained eleven open-ended questions. In each question, a specific barrier recognized in the literature was presented, and then the survey respondents were asked to provide advice on how public librarians can overcome the barrier based on their own experience. The sample of survey respondents was selected using the non-probability sampling method - judgmental sampling (Babbie 2012). Using the member directory of the National Network of Libraries of Medicine (NNLM), a list of 621 full network members that serve health care consumers was compiled. Librarians working at these libraries with the title "Reference Librarian" or "Consumer Health Librarian" were judged to be professional consumer health librarians and thus satisfied the study criteria.

An email message was sent to the each librarian, explaining to them about the purpose and procedures of the study, and inviting them to complete the online survey and share their experience to help public librarians better conduct the consumer health reference interview. Out of the 621 emails, 29 were met with either a delivery failure notice or an "Out of Office" 
automatic response, making the total number of the actual email recipients 592 . The survey was available for three weeks, and a reminder was sent one week before the closing date. A total of 115 completed survey questionnaires were received, indicating a response rate of 19.4\%. For an online survey, this is an acceptable rate. Email has historically tended to be associated with relatively low response rates (Schaefer and Dillman 1998). In Dykema, Stevenson, Klein, Kim, and Day's (2013) research on increasing response rates, they obtained a response rate of $19 \%$ for their email survey. Compared to that, the response rate in this study falls within the reasonable range.

\section{Results}

This section is organized by the survey question. Each question targeted a specific barrier that public librarians encounter when answering consumer health questions. Under each question, the barrier is explicitly described, with support from the literature, and then survey responses are presented to illustrate how to overcome that barrier.

"Q1. What are the information resources that public librarians should become familiar with in order to effectively answer consumer health questions?" (Corresponding barrier - public librarians' limited knowledge of health information resources)

Librarians' familiarity with common health concerns and resources is key to success in providing consumer health information services (Eberle 2005). In Tu's (2007) study about health-related virtual reference services, reference resources in electronic format such as databases and fulltext electronic journal aggregators were rated as the most important types of resources. Public librarians tend be generalists and rarely have special training on health information. Thus, their knowledge of consumer health resources is limited or lacking. Wessel, Wozar and Epstein (2003) 
discovered that public librarians were often unsure what reference books should be used to answer specific disease questions. Linna, Wildemuth, Gollop, Hull, Silbajoris and Monning (2004) surveyed 83 public librarians in North Carolina and found that they rated their knowledge in accessing health information as merely 3.4 on a 5 -piont scale (1=very little and $5=$ a great deal). In a more recent study (Luo and Ta Park 2013), the lack of knowledge about available medical/health information sources was reported by public librarians as one of the top challenges when answering consumer health questions.

To help public librarians expand and enrich their knowledge of health information resources, the survey respondents made a variety of suggestions, as shown in Table 1 . The freely available government resources were most frequently recommended. Particularly, MedlinePlus was recommended by everyone. The respondents believed that "every public librarian should have this site at the top of their list, to help find quality sites on a variety of topics".

\begin{tabular}{|c|c|}
\hline Types of Resources & Examples \\
\hline
\end{tabular}




\begin{tabular}{|c|c|}
\hline & $\begin{array}{l}\text { National Cancer Institute (http://www.cancer.gov/ ) } \\
\text { Centers for Disease Control and Prevention (http://www.cdc.gov/) } \\
\text { Health Information on the Web (https://nnlm.gov/hip/) } \\
\text { HealthCare.gov } \\
\text { USDA Super Tracker(https://supertracker.usda.gov/) } \\
\text { Substance Abuse and Mental Health Services Administration (http://www.samhsa.gov/) } \\
\text { U S Food and Drug Administration (http://www.fda.gov/) } \\
\text { Medicare.gov } \\
\text { Womenshealth.gov } \\
\text { National Guideline Clearinghouse (http://www.guideline.gov/) }\end{array}$ \\
\hline $\begin{array}{l}\text { Websites and publications } \\
\text { of professional medical } \\
\text { organizations/societies }\end{array}$ & 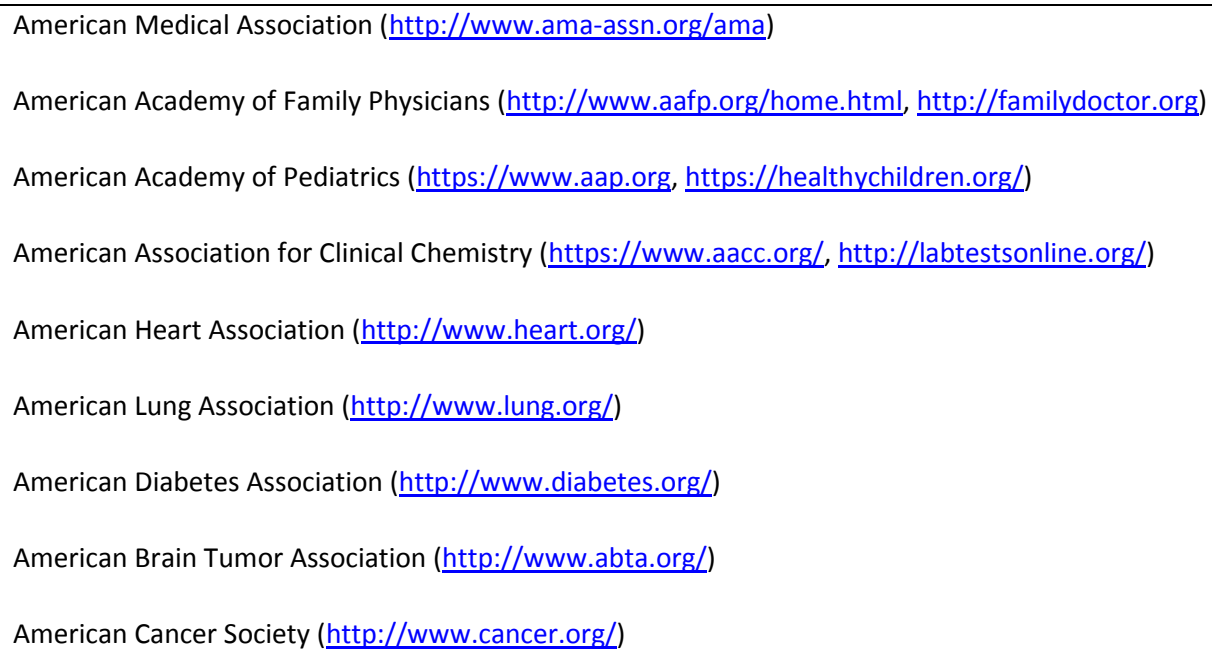 \\
\hline $\begin{array}{l}\text { Websites and publications of } \\
\text { university medical centers and } \\
\text { health care organizations }\end{array}$ & $\begin{array}{l}\text { Mayo Clinic (http://www.mayoclinic.org/) } \\
\text { Integrative Medicine by Memorial Sloan Kettering Cancer Center (https://www.mskcc.org/cancer- } \\
\text { care/treatments/symptom-management/integrative-medicine) } \\
\text { EthnoMed by Harborview Medical Center (http://ethnomed.org/) } \\
\text { Harvard Health Publications ( } \underline{\text { http://www.health.harvard.edu/) }} \\
\text { Tufts University Health \& Nutrition Letter (http://www.nutritionletter.tufts.edu/) } \\
\text { Websites of local hospitals often have free online patient information }\end{array}$ \\
\hline $\begin{array}{l}\text { Websites and publications of } \\
\text { medical and health sciences } \\
\text { libraries }\end{array}$ & $\begin{array}{l}\text { Medical Library Association CAPHIS Section (http://caphis.mlanet.org/) } \\
\text { Medical Library Association Top } 10 \text { Health Websites } \\
\text { (https://www.mlanet.org/resources/medspeak/topten.html) }\end{array}$ \\
\hline
\end{tabular}




\begin{tabular}{|c|c|}
\hline & $\begin{array}{l}\text { SPIRAL (http://spiral.tufts.edu/) } \\
\text { Healthelinks.org } \\
\text { ClicOnHealth ( } \underline{\text { http://rrlc.org/cliconhealth/) }} \\
\text { Consumer Health Toolkit ( } \underline{\text { http://www.library.ca.gov/lds/docs/healthtoolkit.pdf) }} \\
\text { Partners in Information Access for the Public Health Workforce (http://phpartners.org/) }\end{array}$ \\
\hline $\begin{array}{l}\text { Websites of non-profit health } \\
\text { organizations }\end{array}$ & $\begin{array}{l}\text { Nemours Foundation (http://kidshealth.org) } \\
\text { National Organization for Rare Disorders (http://rarediseases.org) } \\
\text { Healthwise (http://www.healthwise.org/) } \\
\text { National Alliance on Mental Illness (https://www.nami.org/) }\end{array}$ \\
\hline .com websites & $\begin{array}{l}\text { Krames Online (http://dhch.kramesonline.com/); WebMD.com; Medscape.com; Patient.com; } \\
\text { Medpagetoday.com; Natural Medicines (https://naturalmedicines.therapeuticresearch.com/) }\end{array}$ \\
\hline Other & $\begin{array}{l}\text { State Board of Medical Examiners website } \\
\text { State's Poison Control hotline. } \\
\text { Support blogs/twitter feeds/chat rooms } \\
\text { YouTube video series "Searcher In Charge: Health Literacy" } \\
\text { (https://www.youtube.com/playlist?list=PL9994DE746E3E63A7) }\end{array}$ \\
\hline
\end{tabular}

Table 1. Information resources that may help public librarians answer medical/health questions effectively

Most of the recommended resources were .gov, .org and .edu websites. Yet, several

respondents mentioned .com sites such as WebMD. This seemed controversial because another respondent expressed opposition against WebMD explicitly - "I would stay away from WebMD".

The use of Google was also controversial - one respondent stated "do not Google for health

related questions", and another believed that it's necessary to use Google and use it well

because "that's what the consumer uses and one needs to understand the client". 
In addition to information resources, the respondents suggested that public librarians become familiar with local/regional medical and consumer health libraries in order to make proper referrals for questions they cannot answer. It is important to know the closest NNLM Regional Medical Library. Each state has an NNLM liaison, equipped to provide training for public librarians.

“Q2. For a public library's core collection of consumer health information, what titles would you suggest? (Corresponding barrier - outdated or inadequate consumer health collection at public libraries)

The public library is expected to meet a broad spectrum of user needs and cannot emphasize health-related services and resources disproportionable to other valued services (Kaiser, 2005). Public libraries often lack information on specific topics that users inquire about, such as a particular disease or drug (Luo and Ta Park 2013). Yet, library users anticipate that public libraries have tailored resources for every special health topic and all of their health information needs can be addressed (Kouame, Harris and Murray 2005).

Public librarians tend to be unsure about what a basic consumer health collection should contain and find it challenging to select materials for such a collection (Sprang and Baker 2000; Wessel et al. 2003). Also, issues related to insufficient funding and staffing may translate into poor, outdated print health collections and few or no subscriptions to consumer health databases and resources (Marshall, Sewards and Dilworth 1991; Benedetti 2002; Kaiser2005). To help public librarians better understand how to develop a consumer health collection, the survey respondents offered the following ideas: 
- Use well-established consumer health bibliographies as a guide. For example, Medical Library Association's Consumer and Patient Health Information Section (CAPHIS) has some collection development core lists (http://caphis.mlanet.org/chis/collection.html), and Connecticut Consumer Health Information Network has a list of recommended books (http://library.uchc.edu/departm/hnet/pdf/corelist.pdf). Other useful lists include Doody's Core Titles, Brandon/Hill selected list of print books and journals for medical libraries, and Barnes \& Noble consumer health titles.

- Health and medical reference books, such as an encyclopedic medicine collection, a good dictionary with appendices that have reference lab values and growth charts, a family health manual, and physician directories.

- Titles covering various medical/health specialties (e.g. anatomy, physiology, pregnancy, child birth, wellness, alternative therapy), drugs, and chronic and diseases (e.g. diabetes, cancer, high blood pressure, and mental health). It is important that the titles are consumer-oriented and not written at a clinical level. For instance, the most useful books about diseases would be those on self-management of the disease and/or special diets.

- Titles from reputable organizations such as the American Cancer Society, American Diabetes Association, American Academy of Pediatrics, American Heart Association, Johns Hopkins Press, Mayo Clinic, Cleveland Clinic, Oxford University Press, Jones and Bartlett, Routledge, JAMA, Merk, Harvard Health, and Krames. 


\section{- Basic health databases such as Gale's Health and Wellness Resource Center and EBSCO}

\section{Health Library.}

Table 2 contains the specific titles suggested by the survey respondents. In addition to the suggestions, one respondent pointed out what kinds of titles to avoid - "skip the diet-of-themonth books and the books with scary or alienating titles (what your doctor won't tell you!) or anything with Miracle or Cure in the title".

\begin{tabular}{|c|c|c|}
\hline Reference Titles & Series & Single Titles \\
\hline $\begin{array}{l}\text { Drug Information } \\
\text { Handbook. } \\
\text { Mayo Clinic Family Health } \\
\text { Book. } \\
\text { Stedman's Medical } \\
\text { Dictionary. } \\
\text { Gale Encyclopedia of } \\
\text { Medicine. } \\
\text { Taber's Cyclopedic } \\
\text { Medical Dictionary. } \\
\text { Complete Guide to } \\
\text { Prescription and } \\
\text { Nonprescription Drugs. } \\
\text { Merck Manual. } \\
\text { Dorland's Illustrated } \\
\text { Medical Dictionary. } \\
\text { Mosby's Dictionary of } \\
\text { Medicine, Nursing \& } \\
\text { Health Professions. } \\
\text { Ferri's Clinical Advisor. } \\
\text { Drug Facts \& } \\
\text { Association Family } \\
\text { Medical Guide. } \\
\text { American Medical } \\
\text { Morisons. } \\
\text { Mong }\end{array}$ & $\begin{array}{l}100 \text { Questions and Answers } \\
\text { series from Jones \& Bartlett. } \\
\text { What to expect when you are } \\
\text { expecting series from } \\
\text { Workman Publishing. } \\
\text { Sourcebook in the Health } \\
\text { Reference Series from } \\
\text { Omnigraphics. } \\
\text { A Parent's Guide to series from } \\
\text { Woodbine House. } \\
\text { MediKidz series. } \\
\text { Living with series from Franklin } \\
\text { Watts. }\end{array}$ & $\begin{array}{l}\text { Introduction to reference sources in the health sciences by } \\
\text { Jeffrey T. Huber and Susan Swogger. } \\
\text { Power Through Pain by Elizabeth Elster. } \\
\text { The Emperor of All Maladies by Siddhartha Mukherjee. } \\
\text { Gut and Psychology Syndrome: Natural Treatment for } \\
\text { Autism, Dyspraxia, A.D.D., Dyslexia, A.D.H.D., Depression, } \\
\text { Schizophrenia by Natasha Campbell-McBride. } \\
\text { Atlas of Human Anatomy by Frank Netter. Healing with } \\
\text { Whole Foods by Paul Pitchford. } \\
\text { Hole's Human Anatomy and Physiology by David Shier and } \\
\text { Jackie Butler. } \\
\text { Essentials of Musculoskeletal Care by John F Sarwark. } \\
\text { Harrison's Principles of Internal Medicine by Dennis Kasper } \\
\text { and Anthony Fauci. } \\
\text { Cecil Textbook of Medicine by Lee Goldman. } \\
\text { Griffith's Instructions for Patients by Stephen W. Moore. } \\
\text { Professional Guide to Diseases by Lippincott. } \\
\text { What to Do When Your Child Gets Sick by Ann Kuklierus and } \\
\text { Gloria Mayer. } \\
\text { Of Pediatrics. }\end{array}$ \\
\hline
\end{tabular}




\begin{tabular}{|l|l|l|}
\hline $\begin{array}{l}\text { Duke Encyclopedia of } \\
\text { New Medicine: } \\
\text { Conventional and } \\
\text { Alternative medicine for } \\
\text { All Ages. }\end{array}$ & $\begin{array}{l}\text { Caring for the Mind: The Comprehensive Guide to Mental } \\
\text { Health by Dianne Hales and Robert Hales. } \\
\text { The } 36 \text { Hour Day: A Family Guide to Caring for People Who } \\
\text { Have Alzheimer Disease, Related Dementias, and Memory } \\
\text { Loss by Nancy L. Mace and Peter V. Rabins . } \\
\text { The Twelve Gifts of Birth by Charlene Costanzo. } \\
\text { Oh, Yuck! : The encyclopedia of everything nasty by Joy } \\
\text { Masoff and Terry Sirrell. } \\
\text { American diabetes Association Complete Guide to Diabetes. } \\
\text { Bowes \& Church's Food Values of Portions Commonly Used } \\
\text { by Jean A. Pennington and Judith S. Spungen. } \\
\text { Be a Survivor by Vladimir Lange. }\end{array}$ \\
\hline
\end{tabular}

Table 2. Titles recommended for a core consumer health collection at a public library

It is also worth noting that $10 \%$ of the respondents indicated that they either didn't have a print consumer health collection or never use print resources to answer consumer health questions. Others also heeded the collection of print titles because they become outdated quickly, as one respondent commented "many books and their medical advice are out of print/inaccurate/not the current recommendations almost as soon as they are printed". However, in a recent study by Luo and Ta Park (2013), public librarians reported that some of their users still prefer print materials and wouldn't trust the printouts of online information. This finding indicates the importance of understanding the library user community and their needs, which was also mentioned by one survey respondent "that would depend on the population served-are they big users of the library for health information, are they technically savvy, would it be best to have ebooks that are rented and retired when no longer current".

"Q3. Public librarians often find it difficult to formulate effective search strategies when answering consumer health questions. Do you have any tips on searching/locating relevant 
medical/health information? (Corresponding barrier - public librarians' inadequate consumer health information search skills)

Tu (2007) identified effective information retrieval to be one of the most important skill sets in her study of health-related virtual reference services. Yet, public libraries found it challenging to use the Internet when answering health-related questions because of the difficulty in formulating effective search strategies (Wessel et al. 2003; Luo and Ta Park 2013).

To help public librarians more effectively search and locate relevant information, the survey respondents suggested the following strategies:

- Different user needs/literacy levels require different sources and different approaches. Thus, it is important to understand what information the user is really looking for and what information they can actually comprehend. Public librarians need to be able to "recognize the difference between a student writing a report, a patient wanting to know about one's own disease pathophysiology, or a patient wanting to know about treatment options, recovery times (how much work will I miss), insurance questions, etc" and "direct efforts to providing appropriate resources for patrons' literacy level".

- The first choice should always be reliable sources such as MedlinePlus, PubMed, or professional associations. MedlinePlus' advantages are well recognized - the information is consumer oriented and easy to understand, the search function is intuitive, and it is an authoritative source with links to trustworthy external sites. PubMed is suited for more advanced information needs and there are free tutorials that public librarians can use to hone their search skills (http://www.nlm.nih.gov/bsd/disted/pubmed.html). 
- Google can be helpful when used to verify spelling. When using Google to search for information, it's important to focus on .org or .gov sites. Using Google Scholar over Google if the user is educated or has some medical/science training, and needs more advanced information.

- Some useful search strategies include 1) start with the simplest possible search string, then use filters to get more specific if need be; 2) use the most recent encyclopedic sources and dictionaries to establish a baseline understanding, and keep notes as the search progresses; 3) use the Patient/Problem/Population, Intervention, Comparison/Control/Comparator (PICO) format to clarify the question, and consider all the possible variations for describing these concepts; 4) use the method that Dialog trainers use - put concepts in separate columns with the synonyms for each in their respective column to be "Or'd" together within the column, and across columns use "and"; and 5) if a database has a thesaurus, use it.

- Evaluating information is critical, as one respondent commented "I'd emphasize evaluating search results over formulating a precise search strategy. For example, a Google search for breast cancer can yield credible results as long as the librarian knows how to interpret those (i.e. from a non-commercial, government, or clinical website)." The "Evaluating Health Information" page from Medline Plus (http://www.nlm.nih.gov/medlineplus/evaluatinghealthinformation.html) is a good place to start learning about how to evaluate online health information.

- Knowledge of basic medical terminology is helpful. 
- It is helpful to take the free courses provided by the National Libraries of Medicine, and it is also advisable to take courses through the Medical Library Association to earn a specialization in consumer health.

- Consult local hospital/medical librarians if the user question is too difficult. ${ }^{1}$

"Q4. Emerging treatments or medications is an area public librarians tend to struggle with. Do you have any recommendations on reliable information resources in this area? (Corresponding barrier - difficulty in locating reliable information on emerging treatments/mediations) Moulton (2008) found that providing information about a new treatment for a rare disorder is one of the hardest and most time-consuming requests reference librarians face. Luo and Ta Park's (2013) study echoed this finding, where public librarians indicated that it is difficult to locate reliable information on emerging treatments and medications.

This challenge is also shared by professional consumer health librarians. One survey respondent commented, "this is also an equally challenging area for seasoned clinical librarians; and even for practicing health care professionals too." To overcome this challenge, the survey respondents emphasized the use of MedlinePlus as a starting point. The two tabs, "Health Topics" and "Drugs and Supplements", are particularly useful. For any health topic, several sections will point to the most current information on new and experimental therapies. For instance, on the HIV/AIDS page, there are sections for Latest News, Treatment, Clinical Trials, Research and Organizations. Organization links will take users to sites where latest research is being conducted.

\footnotetext{
${ }^{1}$ Consulting hospital/medical/health sciences librarians is a ubiquitous theme throughout the responses to all the survey questions.
} 
For recent research on emerging treatments and medications, PubMed and Clinicaltrials.gov were frequently recommended by the respondents. Professional organizations of the disease or condition in question (e.g. American Cancer Society, National Cancer Institute), and the research page of nearby academic medical centers can be helpful too. When searching in PubMed, it would be helpful to limit to clinical trials, randomized controlled trials, metaanalysis, and evidence-based sources. While the majority of the content in PubMed are published research articles and usually too technical for consumers, PubMed reviews geared toward family practitioners or nurses are more readily understood. Nonetheless, it important to recommend that library users discuss the information with their health care provider. For updates about new drugs, the following resources were recommended: Drug Information Portal (http://druginfo.nlm.nih.gov/drugportal/drugportal.jsp), Food and Drug Administration (FDA, http://www.fda.gov), The Medical Letter on Drugs and Therapeutics, Drugs.com, RxList.com, and CenterWatch. For more in-depth research, subscription databases (e.g. Cochrane, Clinical Parmacology, Micromedex, Up-to-date, Clinical Key or Dynamed) are helpful, but public librarians may need to reach out to a local academic medical center or hospital based consumer health information center to access these resources. They may also consider using TRIP (Turning Research into Practice) database. It is a free high-level evidence aggregator that functions similar to an index, but in the event that the full text is made available, direct links are provided.

Sometimes the very latest treatments are mentioned in articles in the popular press. Public librarians may consider using variant terms to conduct Google searches to find out the physicians, medical school, or health system that uses a new treatment. Following institutional 
health newsletters such as Harvard Health and FDA alerts can also be an efficient way to keep up with new medical developments. Online patient communities such as PatientsLikeMe.com or forums dedicated to certain conditions may have useful information as well.

In addition, the respondents warned about the complicated nature of emerging treatments, as indicated in these comments - "Emerging treatments are tough" , "new treatments are a minefield; take every information source with a grain of salt" , and "help them [library users] understand that emerging treatments are often later found to be invalid" . They stressed the importance of avoiding pharmaceutical-sponsored sites and focus on the most authoritative sources.

“Q5. What are the strategies to effectively evaluate the readability of medical/health information in order to determine its appropriateness for a user's literacy level? (Corresponding barrier - difficulty in locating and identifying medical/health information appropriate for users' literacy level)

In Luo and Ta Park's national survey of public librarians (2013), they found that a common challenge faced by public librarians was that much of the medical/health information was written at a professional level and it was difficult for them to determine the appropriateness of the information for users' reading comprehension. To overcome this challenge, two ideas were suggested. First, use established formulas to assess the technical level of the information. The health literacy movement has spawned many resources for evaluating readability, such as the Fry method, Free Text Readability Consensus Calculator (http://readabilityformulas.com/freereadability-formula-tests.php), Simple Measure of Gobbledygook (SMOG) Readability Index 
(http://www.readabilityformulas.com/smog-readability-formula.php), Flesch-Kincaid Grade Level (http://www.readabilityformulas.com/flesch-grade-level-readability-formula.php), the CDC Clear Communication Index, SAM, Fog, and Microsoft Word's readability feature. These formulas usually involve measuring the sentence length and number of syllables in words. Easy-to-read materials tend to have simple words with fewer syllables, less text and more images, information is broken into small chunks, more white space, less technical jargon, more plain language and more video or audio content. It is always helpful to check a website's About Us page to see if grade level or intended audience is given.

Secondly, never assume a high health literacy level and start with easier to read information, as one survey respondent commented, "I tend to err on the lower level of literacy as my default method of communication". MedlinePlus was once again repeatedly mentioned as an exemplar source - it has an Easy-to-Read section on their website (http://www.nlm.nih.gov/medlineplus/all_easytoread.html), and MedlinePlus summaries are typically written on a 5th-8th grade level. Other sources of easy-to-read material include professional organizations' patient education handouts, brochures, and worksheets, databases that are more publicly oriented like EBSCOHost, patient and caregiver sections on government or non-profit websites, and patient information in medical databases like UpToDate.

The survey respondents also alluded to the importance of determining the library users' health literacy level and therefore finding the most appropriate information for them. This issue is also covered in the survey questionnaire and will be addressed later in the Results section. 
“Q6. Please suggest some open-ended or neutral questions that are useful in clarifying users' information needs in consumer health reference interview. You may make up to 5 suggestions. (Corresponding barrier - difficulty in interpreting library users' health information needs)

In Luo and Ta Park's (2013) study to assess public librarians' training needs for consumer health information services, $61.8 \%$ of the librarians reported having difficulty interpreting healthrelated questions from users. Benedetti (2002) opined that the confusion in health reference interview could be generated by users' own circle of family or friends, who may give inaccurate information and increase the user's anxiety level. It is also likely that users may have forgotten a great deal of what the doctor discussed with them by the time they come to the library, or they may be asking for information on behalf of someone else.

Thomas (2005) encouraged librarians to adopt a patient-centered interview style that seeks to uncover the real information need. Allcock (2000) suggested using open-ended questions to help elicit a more detailed response and rephrasing the user's response and repeating it back to clarify their information needs. Thomas (2005) and Eberle (2005) believed that librarians should have some ready lines, and use tried and true interview techniques and personalized them in their own health reference interview. Following their suggestions, this survey asked consumer health professionals to provide sample clarifying questions they find useful in their own experience. Table 3 presents a summary of the types of questions they often use when helping users with health-related questions. 


\begin{tabular}{|c|c|}
\hline Interview & \\
\hline $\begin{array}{l}\text { Questions that encourage users } \\
\text { to elaborate on their information } \\
\text { needs }\end{array}$ & $\begin{array}{l}\text { - Can you tell me more about what you want/need to know regarding x } \\
\text { condition or disease? } \\
\text { - How can I best help you with your question? } \\
\text { - Tell me briefly and only as much as you want to share about your or your } \\
\text { friend's health concern and what you'd like to know. }\end{array}$ \\
\hline $\begin{array}{l}\text { Questions seeking to understand } \\
\text { what users already about the } \\
\text { topic }\end{array}$ & $\begin{array}{l}\text { - Where have you tried looking already? } \\
\text { - What information have you already found on this topic? } \\
\text { - What have you already read, seen, or heard about it? }\end{array}$ \\
\hline $\begin{array}{l}\text { Questions aiming to determine } \\
\text { how users intend to use the } \\
\text { information }\end{array}$ & $\begin{array}{l}\text { - It would help me to understand how you intend to use this information. } \\
\text { - What is this information for (health care decision, school project, curiosity, } \\
\text { etc.)? }\end{array}$ \\
\hline $\begin{array}{l}\text { Questions seeking to clarify the } \\
\text { condition/treatment that users } \\
\text { inquire about }\end{array}$ & $\begin{array}{l}\text { - I am not familiar with that term. Do you have its spelling? } \\
\text { - What part of the body does this involve? } \\
\text { - What did you doctor say, have you written it down for me to look at? } \\
\text { - } \text { myere did you hear the term? (response could be: evening news; diagnosis; } \\
\text { - } \quad \text { Have you been given a diagnosis? } \\
\text { - Is this a new diagnosis? } \\
\text { - What is the drug treatment for? } \\
\text { - } \quad \text { I think you are saying you need information about..... is that right? }\end{array}$ \\
\hline $\begin{array}{l}\text { Questions seeking to identify the } \\
\text { specific aspect of the topic }\end{array}$ & $\begin{array}{l}\text { - What about the disease are you looking for - i.e., symptoms, treatment, } \\
\text { diagnosis, or prognosis? } \\
\text { - There are many types of cancer. What type would you like to know about? } \\
\text { - Try to get as specific information as possible, i.e., if someone asks for } \\
\text { information on Paget's disease are they talking about bone or breast? } \\
\text { - Do you need current or historical information? }\end{array}$ \\
\hline $\begin{array}{l}\text { Questions eliciting details about } \\
\text { the audience of the information }\end{array}$ & $\begin{array}{l}\text { - Are you finding this information on behalf of another person? } \\
\text { - Do you have access to the internet? } \\
\text { - Would you prefer that I look for research articles or the same literature your } \\
\text { doctor may read, or do you want something more "plain language?" }\end{array}$ \\
\hline $\begin{array}{l}\text { Questions about users' preferred } \\
\text { format/length/language of the }\end{array}$ & $\begin{array}{l}\text { - Do you prefer graphics (pictures), text (words) or videos (Youtube)? } \\
\text { - What language do you need the information in? } \\
\text { - Would you like me to show you how to use some of the available online }\end{array}$ \\
\hline
\end{tabular}




\begin{tabular}{|l|cl|}
\hline information & $\begin{array}{l}\text { resources or would you prefer that I find you a book or handout you can take } \\
\text { with you? }\end{array}$ \\
\hline $\begin{array}{l}\text { Questions verifying the fulfillment } \\
\text { of users' information need }\end{array}$ & $\begin{array}{l}\text { - How well does this (article, information) answer your question? } \\
\end{array}$ & $-\quad$ Is this helping? Is this information helpful or do you need more? \\
\hline
\end{tabular}

Table 3. Examples of neutral and open-ended questions to clarify users' health information needs

7. Sometimes users are reluctant to be specific about their inquiries due to various reasons (e.g.

sensitive or stigmatized topics, personal characteristics). How would you go about eliciting as

much information from them as possible, without making them feel uncomfortable?

(Corresponding barrier - users unwilling to disclose specifics about their conditions/diseases in consumer health reference interview)

A well-acknowledge barrier in consumer health reference interview is that sometimes users are reticent or reluctant to disclose their concerns (Marshall et al. 1991; Borman and McKenzie 2005; Thomas 2005; Luo and Ta Park 2013). Reasons behind the reticence or reluctance may include a stigmatized topic, individual characteristics, and the environment (Kouame et al. 2005). Allcock (2000) pointed out that the reference interview would be limited by the degree to which the patron shares the nature of their concern. Borman and McKenzie (2005) identified attentiveness, neutrality, discretion, and respect for privacy as the most important qualities gain trust and acceptance from users who are unwilling to share the details of their conditions. And yet, knowing when to ask for more details, how to ask, and when to refrain from asking, requires extreme tact (Eberle 2005; Thomas 2005).

In this survey, consumer health librarians shared their experience and offered the following suggestions on helping reluctant patrons: 
- Offer to have the conversation in a private and safe location, and ensure the confidentiality of the conversation.

- Build rapport through positive body language (e.g. warm and relaxing smile) and active listening, as shown in this remark "I listen to them, I demonstrate they can trust me and that I am a stickler for confidentiality. I also do not allow for any interruptions - they have my full, undivided attention. It takes time...but once they feel safe and heard, they often open up with specific details"

- Show compassion and sympathy, but be neutral, non-judgmental and professional, as indicated in these comments - "the more matter of fact I am with the customer, the less they feel uncomfortable" and "if you can say "bowel movement" without embarrassment, they can too".

- Patiently explain to users why librarians need to ask clarifying questions - to best help them find what they need.

- Never assume that the person asking the question is the person with the medical condition.

- Provide a range of options for users to ask questions and receive help - for instance, have users fill out a request form or write down their questions, or suggest basic and general information (e.g. a medical encyclopedia or MedlinePlus) for them to view in private, and check back with them to see if they have any questions. 
- Ask generic questions that could lead to what users are looking for without necessarily making them divulge personal information (e.g. are you looking for treatment information; are you looking for drug information?).

“Q8. How would you respond to users whose inquires are vague or incomplete due to their limited medical terminology or inadequate knowledge of the topic? (Corresponding barrierusers being vague in communicating their health information needs due to limited medical knowledge)

Users incomplete or unclear inquires often result from their lack of adequate knowledge of the topic they inquire about (Wessel et al. 2003; Kouame et al. 2005; Luo and Ta Park 2013). For instance, they may have an incomplete understanding of the medical terminology they have heard and there are often secondhand communication breakdowns (Thomas 2005). Thus, they provide incorrect spelling or pronunciation of the medical terms in their questions, making it challenging for librarians to interpret and answer them. Allcock (2000) and Thomas (2005) suggested that it may be more appropriate to send the user back to the health care professional in order to verify information on the personal condition prior to seeking more information based on a vague reference. They believed that it is not up to the librarian to try to guess what the user means. In fact, it is essential that librarians learn that they should get used to saying "call your doctor".

The survey respondents mostly agreed with Allcock (2000) and Thomas (2005). They did acknowledge that it is helpful to use probes to clarify, as shown in this exemplar quote, "one father asked for info on imperfininis. I asked him what was going on with his baby and he said the baby couldn't poop. That is how I knew he wanted "imperforate anus." Sometimes I ask 
them to tell me what body part is involved, or which clinic they go to (so I know if they are talking Gl or neuro or surgical or what)". However, it is important to never make farfetched guesses. When an inquiry is too vague, it would be necessary to ask the user to check with their doctors for more precise details, as one survey respondent commented, - "You do not want to guess at the diagnosis. Often patients are unsure of the name of the condition and may say things like I think it's a cancer and it starts with a c. I always let them know that I would love to help them but don't want to guess and give them the wrong information."

“Q9. Public librarians find it challenging to gauge users' literacy level in order to provide the most appropriate information for them. Do you have any useful strategies to share?

(Corresponding barrier - difficulty in assessing users' literacy level in consumer health reference interview)

Many librarians were concerned with the issue of health literacy (Eberle 2005). Users often find medical vocabulary daunting and confusing, and they can be highly educated but have little or no familiarity with medical terminology (Thomas 2005). Thus, it is important for librarians to properly assess users' literacy level and provide information that are comprehensible to them (Eberle 2005). Thomas (2005) suggested obtaining literacy rates for the appropriate geographical area from the national institute for literacy, and becoming wary of low literacy clues - asking for a video instead of written materials, limited English-speaking skills, declining a printed brochure when offered, and bringing along a family member as a helper.

In this survey, respondents shared the following strategies they found useful in assessing users' literacy level: 
- Assume low literacy level. People are under stress when they have a health concern, and that alone lowers their ability to take in information. A respondent even shared a personal story to illustrate this point - "I am a graduate degreed health science librarian, but when I was diagnosed with cancer, my literacy level at that moment was not to be trusted by librarians that served me."

- Start with consumer-oriented sources like MedlinePlus and observe how users respond to them. If they express an interest in images or pictures, this could be an indicator that they have difficulty reading. If they find the information too basic and request new or advanced research, this would mean that they have a higher literacy level.

- Assess the vocabulary used by the user when describing their questions - are they using medical jargon correctly, are they struggling with medical terms, can they explain what they are looking for coherently?

- Ask proper questions in the reference interview to glean information about the user's literacy level, such as 1) what their background is on this topic, and how much they already know or have read about it (e.g. if a person has had a long standing diagnosis of diabetes, they will not want introductory information, and may be asking for latest treatments or genetic information); 2) whether they have computer and internet access; 3) how they rate themselves as a reader; and 4) what types of information they prefer (e.g. journal articles, books, pamphlet, videos, information written for lay people, nurses or doctors). 
“Q10. What are your suggestions on handling difficult user behavior? (Corresponding barrierchallenges in handling difficult user behavior in consumer health reference interview) Eberle (2005) pointed out that library users with mental illness may be difficult to work with because they tend to be nervous, stressed, or agitated and emotional states could promote unreasonable expectations of the librarian. In this survey, the respondents added that library users can be emotional and upset as they are working through their anxiety and angst over a newly diagnosed, terrifying health situation. It is important that librarians do not take their attitude personally. Being a patient listener can be helpful, as one respondent commented, " $a$ lot of times they just need someone to listen to them so I will listen and let them vent; that will often allow them to calm down."

When handling users with unreasonable demands, the respondents suggested setting a limit on the number of inquiries they could submit during a certain period of time, the number of articles that could be printed out for them, and the amount of time the librarian can spend on their inquiry while there are others waiting. It is also advisable to ask a colleague for help, and one respondent shared the idea of having "some sort of signal or code so other staff can assist if needed."

Overall, the respondents all agreed that it is crucial to maintain professionalism when users exhibit difficult behavior - be patient, calm, empathetic, and polite, and in the meantime be firm, especially about the extent of assistance the librarian can provide. Reassuring language can be helpful in rapport-building, such as "I can understand why this is frustrating for you," and "let's work together to find some information that you can discuss with your care team." One respondent suggested placing scripted statements at the reference desk (out of user's sight) 
that the librarian may use as a guide to craft their responses. If the difficult situation escalates and the user demonstrates harmful intent in any way, the librarian' s first responsibility should be the safety of him/herself and of others. It would be necessary to remove him/herself from the situation and call security from a safer environment .

“Q11. Do you have any suggestions to help public librarians avoid liability in answering consumer health questions? (Corresponding barrier - challenges in walking the ethical tightrope of providing health information while not providing health advice) A major concern for public librarians is the ethical obligations to provide access to published medical information while not providing medical advice (Sprang and Baker 2000). Library users tend to blur the line between health information and health advice and they do not understand that librarians' role is limited to helping them with health information needs and not offering health advice (Kouame et al. 2005). Allcock (2002) acknowledged that the temptation exists to research and digest information for the user, filtering information through the librarian's personal biases. Lacking expertise in medical/health information resources, public librarians often feel pressed to assist individuals in interpreting and understanding information without giving the impression of offering advice (Wessel et al. 2003). They also find it difficult to effectively communicate the role of the librarian to library users - librarians are not medical/health professionals and, therefore, are not qualified to offer advice; their role is to assist users in locating the information they need (Luo and Ta Park 2013). In response to this challenge, the survey respondents suggested the following two ideas: 
- Put a disclaimer in visible places (e.g. on pamphlets or other print documents related to the library's consumer health information services; on a sign near the print consumer health collection; on the consumer health information section of the library Website. Exemplar disclaimer language shared by the survey respondents included:

o "The information contained in these documents is presented for the purpose of educating consumers on wellness and disease management topics. Nothing contained in these documents is intended to be instructional for medical diagnosis or treatment. The information should not be considered complete, nor should it be relied on to suggest a course of treatment for a particular individual. It should not be used in place of a visit, call, consultation or the advice of your physician or other qualified health care provider. Information obtained in these documents is not exhaustive and does not cover all diseases, ailments, physical conditions or their treatment. Should you have any health care related questions, please call or see your physician or other qualified health care provider promptly. Always consult with your physician or other qualified health care provider before embarking on any new treatment, diet or fitness program. You should never disregard medical advice or delay in seeking it because of something you have read in these documents."

o "Published health information, in print or online, is meant to be informative but cannot replace professional advice from a doctor familiar with your medical condition. Do not start or change a treatment without consulting your doctor." 
- Never interpret medical information or offer personal opinions/stories. Librarians should only provide information from reliable and reputable sources, and ask library users to read it and discuss with their healthcare providers. The quotes below were specific and practical suggestions from the survey respondents.

o "Say 'I'm not a doctor' frequently".

o "Always, ALWAYS, tell patrons that you can help them to locate health information, but that the information is most often general and does not apply to every patient."

o "Do not 'advise' or 'recommend' any treatment of any kind. Do not offer any medical judgments of any kind 'my cousin had something very similar and her doctor said it was ...' Remind people to discuss treatments and diagnoses with their doctor, and to ask their doctor any medical questions. Remind people that the information you are giving them is based on their question, not on your judgment about them or their condition".

o "If patrons come to you with something they cannot understand, I tell them to photocopy it, or I will photocopy it and have them highlight the areas of confusion. I then would tell them to take it to their health provider and ask them to explain".

o "If someone asks for some specific information, like a definition, I read precisely what is written without any interpretation. If they still don't understand, they need to highlight and ask their provider". 
o "Refer them to resources but the most you can say is "It sounds from what you tell me like this might help you with that, but I am not a doctor...' If they ask you, 'Does this mean...?' tell them you can't say that. Refer them to their doctor, nurse line, or community clinic".

o "Remember that librarians cannot make diagnoses. Consumers will often provide a list of their symptoms and want information on the related disease/condition - thereby asking for a diagnosis. If librarians do so they are practicing medicine without a license. Always ask for the diagnosis, supplied by their health provider."

\section{Discussion}

Seeking the input from professional consumer health librarians, this study presents an up-todate view on how to help public librarians overcome the barriers in consumer health reference transactions and successfully conduct the reference interview. As shown in the literature review, most of the existing literature on this topic is more than a decade old and primarily comprised individual librarians' perspectives or individual libraries' experiences in preparing public librarians for consumer health information services. Toward the continued enrichment and update of the topical knowledge, this study employs a fresh approach to examine the consumer health reference interview in public libraries by involving professional consumer health librarians in the conversation and asking them to share their perspectives and experiences.

Various suggestions are provided about interpreting library users' information needs, gauging users' health literacy level, locating/searching/evaluating consumer health information, and 
communicating the information to users. Among them, a notable finding is the universal advocacy for MedlinePlus as a starting point when answering medical/health questions. It is a comprehensive, reliable government Website that is consumer-oriented and can lead to many other credible and more specialized sources. Particularly, for public librarians, who usually do not have access to medical/health databases, the mastery of MedlinePlus can be a useful first step toward building a solid knowledge base of consumer health information. Therefore, when designing training programs to prepare public librarians for consumer health information services, MedlinePlus should be included as a core resource and covered extensively. The examples of neutral and open-ended questions to clarify users' health information needs constitute a concrete way to for public librarians to visualize the different routes to pinpoint what exactly the user is inquiring about. It might be helpful for librarians to memorize some of the "ready lines" and the purposes they serve, so that they can save time in the reference interview. According to Wessel et al. (2003), public librarians often have limited time available for medical/health questions. Thus, a built-in repertoire of clarifying questions can help librarians be more efficient in identifying users' genuine information needs and addressing them.

Matching users with health information most appropriate to their literacy level is critical. In this study, ideas are gathered regarding how to assess the technical level of health information and the health literacy level of library users. A variety of formulas can be used to gauge a website's readability, and public librarians may consider bookmarking them on the computer at the reference desk. The assessment of users' literacy level is not as straightforward. Among the different suggestions, it is worth noting the safe route - assume low literacy level and start with 
relatively easy to read sources like MedlinePlus. The reasoning for the safe route is that when people are facing a new diagnosis, they are often stressed and fragile, which lowers their ability to understand information, and it helps to ease them into the information seeking process and they can always request more advanced information if their needs are not met. This reflects an important aspect of providing consumer health information at public libraries - understanding why users bring their medical/health questions to public librarians.

More than three decades ago, Rees (1982) pointed out that individuals seeking help from librarians are often motivated by "the desire to identify, alleviate, and remedy diseases and ailments; by the need to preserve health and prevent disease; and by the desire to access supporting services in their communities that can assist them in coping with the financial, social, and economic impact of illness". This statement still rings true at nowadays. When someone approaches the reference desk with a medica/health question, their purpose could be to find information for themselves, a family member, or close friend. Often the information need stems from a medical diagnosis or symptom. Users may come to the library before their doctor's visit in order to research their symptoms, or after receiving news at the doctor's office (Allcock 2000; Kaiser, 2005). If they have not received appropriate assistance from health care providers, or experienced difficulty in find outing about or connect with health care professionals/agencies, they are more likely to use the public library because it is a neutral, approachable, well-connected agency that will provide users with information or make referrals to other organizations that are difficult to discover (Borman and McKenzie 2005). A clear understanding of what motivates users to come to the public library with medical/health 
questions, will contribute to librarians' more effective and efficient application of the reference interview tactics yielded in this study in helping users fulfill their information needs.

A repeatedly emerging theme in this study is recommendations that public librarians consult hospital/medical/health sciences librarians if they couldn't answer the question themselves. However, Kouame et al. (2005) recognized that there is a sense of intimidation by medical librarians among public librarians, which makes them hesitant to contact medical librarians for assistance about consumer health questions. This feeling of intimidation could be assuaged and public librarians may feel more encouraged to reach out to medical librarians if partnerships can be formed between public libraries and medical libraries. Benefits of such partnerships are well acknowledged in the literature, and NNLM has provided regular funding for them (Lyon 2001; Snyder, Huber and Wegmann 2002; Kaiser, 2005; Wessel et al. 2005; Eberle 2005; Smith, Logsden and Clark 2005). Kaiswer (2005) summarized the popular partnership models: 1) train the trainer - medical libraries helping public librarians master the necessary skills and knowledge in assisting users with medical and health information needs; 2 ) the creation of a consumer health website to serve as a local regional or national portal to quality information. Public libraries may consider connecting with the regional offices of NNLM (https://nnlm.gov/about/contact us.html) to discuss the possibilities of partnerships and determine the best ways to draw upon the expertise and resources of medical libraries to help the public with their health information needs.

Specialized training on consumer health information is an effective way for public librarians to become adequately prepared to answer medical/health questions. In this study, a number of training resources are mentioned, such as the consumer health information classes offered by 
the Medical Library association (https://www.mlanet.org/education/chc) and the American Library Association (http://www.ala.org/rusa/development/healthinfo). Findings of this study may also be used to refine the training materials as they represent the voices of experienced consumer health librarians. It is understandable that public librarians may not have the time or monetary support to take advantage of these classes, and that is one of the reasons for conducting this study. Through systematically reporting practical strategies to overcome barriers in consumer health reference interview, this study provides direct and concrete knowledge that could help public librarians better understand the essence of consumer health information services and become more confident and competent in assisting users with their health information needs.

\section{Conclusion}

Public libraries are a crucial venue for people to access reliable, credible and current health information. With the passing of the Affordable Care Act, more and more people are seeking help from public librarians as they navigate the complex health care system and make health care decisions (Liu 2014, personal communications). Thus, it has become increasingly important for public librarians to be well equipped with the knowledge and skills to properly answer users' medical/health questions. To that end, this study has identified the barriers public librarians face when conducting the consumer health reference interview from a comprehensive literature review, and elicited ideas from professional consumer health librarians on overcoming them. It is the author' s hope that this study will provide public librarians with a systematic, thorough and concrete understanding of how to appropriately 
interpret users information needs, gauge their literacy level, and searching/locating/evaluating/communicating the most relevant, reliable and credible health information to them. Educators may also benefit from this study and use the findings to enhance the content and delivery of consumer health information training. Adequately prepared public librarians will lead to optimized user experiences, which will ultimately contribute to the improvement of the collective health literacy level of our citizenry.

\section{References}

1. Allcock, J. C. 2000. "Helping public library patrons find medical information - the reference interview.” Public Library Quarterly 18(3/4): 21-27.

2. Babbie, E. 2012. The practice of social research, Belmont, CA: Wadsworth Publishing.

3. Baker, L. M., and V. Manbeck. 2002. Consumer health information for public librarians, Lanham, MD: Scarecrow Press.

4. Benedetti, J. M. 2002. "Strategies for consumer health reference training." Health care on the Internet 6(4): 63-71.

5. Borman, C. B., and P. McKenzie. 2005. "Trying to help without getting in their faces: Public library staff descriptions of providing consumer health information." Reference \& User Services Quarterly 45(2): 122-46.

6. Dykema, J., J. Stevenson, L. Klein, Y. Kim, and B. Day. 2013. "Effects of e-mailed versus mailed invitations and incentives on response rates, data quality, and costs in a web survey of university faculty." Social Science Computer Review 31: 359-370. 
7. Eberle, M. L. 2005. “Librarians' perceptions of the reference interview.” Journal of Hospital Librarianship 5(3): 29-41.

8. Kaiser, J. 2005. "Promoting improved access to consumer health information." Indiana libraries 24(3): 20-22.

9. Kouame, G., M. Harris, and S. Murray. 2005. "Consumer health information from both sides of the reference desk." Library Trends 53(3): 466-79.

10. Lyon, B. J. 2001. "The National Library of Medicine and health information for the public.” Public Libraries 40(2): 107-109.

11. Linnan, L., B. M. Wildemuth, C. Gollop, P. Hull, C. Silbajoris, and R. Monnig. 2004. "Public librarians as a resource for promoting health: Results from the Health for Everyone in Libraries Project (HELP) Librarian Survey.” Health Promotion Practice 5(2): 182-90.

12. Luo, L., and V. Ta Park. 2013. "Preparing public librarians for consumer health information service: A nationwide study.” Library and Information Science Research 35(4): 255-239.

13. Marshall, J. G., C. Sewards, and E. L. Dilworth. 1991. "Health information series in Ontario public libraries.” Canadian Library Journal 98: 37-44.

14. Moulton, S. E. 2008. " Reference response to a consumer health query." Journal of Consumer Health on the Internet 12(3): 2008. 
15. National Network of Library of Medicine (NNLM). 2014. "The consumer health reference interview and ethical issues.” http://nnlm.gov/outreach/consumer/ethics.html

16. Orban, E. 2005. "Health literacy: Challenges and implications for consumer health librarians.” Indiana Libraries 24(3): 2-6.

17. Parker, R., and G. L. Kreps. 2005. Library outreach: Overcoming health literacy challenges. Journal of the Medical Library Association 93(4): 81-85.

18. Rees, A. M. 1982. Developing consumer health information services, New York: R. R. Bowker Company.

19. Schaefer, D. R., and Don A. Dillman. 1998. "Development of a Standard E-Mail Methodology.” Public Opinion Quarterly 62: 378-97.

20. Smith, C., K. Logsden, and M. Clark. 2005. "Consumer health information services at Iowa City Public Library.” Library Trends 53(3): 496-511.

21. Snyder, M., J. T. Huber, and D. Wegmann. 2002. "Education for consumer health: A train the trainer collaboration." Health Care on the Internet

22. Sprang, L., and L. M. Baker. 2000. "Healthcare information delivery in public libraries: Implications for academic reference librarians.” Reference Services Review 28(1): 81-94.

23. Thomas, D. 2005. "The consumer health reference interview." Journal of Hospital Librarianship 5(2): 2005. 
24. Tu, F. 2007. "Knowledge and skills required to provide health information-related virtual reference services: Evidence from a survey.” Journal of Medical Library Associations 95(4): 458-460.

25. Wessel, C. B., J. A. Wozar, and B. A. Epstein. (2003). "The role of the academic medical center library in training public librarians.” Journal of Medical Library Association 91(3): 352-360.

26. Westermann-Cicio, M. L. 2003. "Bringing quality electronic information to the health care consumer: Library collaborations that work." Journal of Consumer Health on the Internet 7(1): 2.

27. Wood, F. B., B. Lyon, M. B. Schell, P. Kitendaugh, V. H. Cid, and E. R. Siegel. 2000.

"Public library consumer health information pilot project: Results of a National Library of Medicine evaluation.” Bulletin of the Medical Library Association 88(4), 314-322.

28. Zionts, N. D., J. Apter, J. Kuchta, and P. K. Greenhouse. 2010. “Promoting consumer health literacy: Creation of a health information librarian fellowship.” Reference \& User Services Quarterly 49(4): 350-59. 